\begin{tabular}{|c|c|c|}
\hline W & $\begin{array}{l}\text { Journal of Innovative Engineering } \\
\text { and Natural Science } \\
\text { (Yenilikçi Mühendislik ve Doğa Bilimleri Dergisi) }\end{array}$ & (JIENS \\
\hline Araştırma Makalesi & journal homepage: https://jiens.org & \\
\hline
\end{tabular}

\title{
Metalotermik FeMn üretiminde magnezotermik ve aluminotermik yöntemlerin karşılaştırılması ve redüksiyon sistemlerinin termodinamik modellenmesi
}

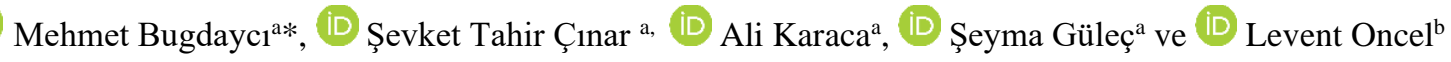

${ }^{a}$ Yalova Üniversitesi, Kimya Mühendisliği, Yalova Üniversitesi Merkez Kampüs Mühendislik Fakültesi, Yalova/77200, Türkiye.

${ }^{b}$ Sinop Üniversitesi, Metalurji ve Malzeme Mühendisliği, Mimarlık Mühendislik Fakültesi, Sinop/57000, Türkiye.

MAKELE BİLGİSI

Makale Geçmişi:

Geliş: 1 Mayıs 2021

Düzeltme: 10 Mayıs 2021

Kabul: 16 Mayıs 2021

Çevrimiçi mevcut

Anahtar Kelimeler:

FeMn

Metalotermik Redüksiyon

Termodinamik Modelleme

Tufal

Geri Dönüşüm

\section{ÖZET}

Çelik malzemelerin dökümünde karşılaşılan zorlukların üstesinden gelmek ve mekanik özelliklerini geliştirmek için, ferroalaşımlar yaygın bir biçimde kullanılan malzemelerdir. Bu malzemeler genel olarak yüksek maliyet ve enerji gereksinimi olan yöntemler ile üretilmektedir. Bu çalışmada bu alaşımlardan biri olan FeMn alternatif bir metot olan metalotermik redüksiyon ile üretilmiştir. Redüksiyon sistemleri FactSage 7.1 programı ile modellenmiştir. Çalışmada demir kaynağı olarak Tufal ve Hematit, Manganez kaynağı olarak da MnO kullanılmıştır. Redüksiyon sistemlerinde indirgeyici olarak Mg ve Al kullanılmıştır. Deneysel çalışmalarda kullanılan Tufal üretilmiş çelik yüzeylerde soğuma esnasında oluşan demir oksitçe zengin yapıdır. Bu malzemenin geri dönüşümü önem arz etmektedir. Bu çalışmada malzeme hammadde olarak değerlendirilerek redüksiyon koşulları incelenmiştir.

2021 JIENS Tüm hakları saklıdır.

Comparison of magnesiothermic and aluminothermic methods in metallothermic FeMn production and thermodynamic modeling of reduction systems

\section{ARTICLE INFO}

Article history:

Received 1 May 2021

Received in revised form 10 May 2021

Accepted 16 May 2021

Available online

\section{Keywords:}

FeMn

Metallothermic Reduction

Thermodynamic Simulation

Millscale

Recycling

\begin{abstract}
Ferroalloys are widely used materials to overcome the difficulties encountered in casting steel materials and to improve their mechanical properties. These materials are generally produced with methods that require high cost and energy. In this study, FeMn, one of these alloys, was produced by metallothermic reduction, which is an alternative method. The reduction systems are modeled with the FactSage 7.1 program. In the study, Millscale and Hematite were used as a source of iron, and $\mathrm{MnO}$ was used as a source of Manganese. $\mathrm{Mg}$ and $\mathrm{Al}$ are used as reductants in reduction systems. Millscale used in experimental studies is an iron oxide-rich structure formed during cooling on steel surfaces produced. Recycling of this material is important. In this study, the reduction conditions have been investigated by evaluating the material as a raw material.
\end{abstract}

2021 JIENS All rights reserved.

\section{GİRIŞ}

Metalürji endüstrisinde, ferroalaşımlar, refrakterler ve antioksidanlar gibi oksijensiz bileşik içeren birçok malzeme kullanılmaktadır. Ferromanganez bu alaşımlardan biri olup; \%78 oranında manganez içerir ve demirçelik sanayinde kullanılır. Manganez elementi; demir bazlı alaşımlarda sertlik, tokluk, aşınma direnci ve 
mukavemet gibi özellikleri attırdığı için ve antioksidan özelliklerinden dolayı çelik üretimi için oldukça önemlidir. Ayrıca; alüminyumla alaşımlandırılmış formunun, korozyon direnci oldukça yüksektir. Dünyada demir-çelik sanayinde; üretilen manganezin $\% 90-95$ 'i ferromanganez ve ferrosilikomanganez olarak kullanılmaktadır. Ayrıca Türkiye'de de çelik üretilirken bu manganez alaşımlarından faydalanılmaktadır [1-3].

Ferromanganez, genel olarak yüksek firınlarda veya elektrik ark ocaklarında MnO'in indirgenmesiyle üretilirken; bu yönteme ek olarak endüstriyel bazda kullanılması için metalotermik redüksiyon yöntemiyle retim koşulları da araştırılmaktadır [4]. Ferroalyajlar ve intermetalik bileşikler ile birlikte çok çeşitli metaller ve alaşımlar üretmek için kullanılan bu yöntemin tercih edilmesi ve incelenmesindeki önemli faktörler; kısa işlem süresi ve yüksek saflıkta karbon içermeyen ürün elde edilebilme olanağıdır [5-7].

Ayrıca manganez (Mn) içeren demir alaşımlı dökümde, şarjdaki Mn miktarı \%20'yi aştığında eriyik çok viskoz bir yapıya dönüşür. Metal akışındaki zorluk nedeniyle malzemenin dökümü çok zordur. Ayrıca kalıpta dökülen malzemenin katılaşma aşaması da oldukça sorunludur. Metalden yeterli akışkanlık elde edilemediği için, kalıp hızla bozulmalı ve numune çabuk soğutulmalıdır $[4,8-11]$

Tüm bu sorunlar göz önüne alındığında sıvı demir banyosuna FeMn olarak Mn eklenmesi işlemi çok daha kolay hale getirecektir. Çünkü çeliğin sıvı fazında malzeme benzer yoğunlukta olacak ve istenilen bileşim kolaylıkla elde edilecektir. Viskoziteyi artırmadan döküm yapmak, yukarıda bahsedilen sorunları önleyecektir [12-15].

Metalotermik redüksiyon yöntemi, kendi enerjisini kendi üreten, basit bir proses olması açısından avantajı bir yöntem. Bu yöntemin en büyük dezavantajı pahalı redüktan gereksinimidir. Fakat metalotermik redüksiyon yönteminin geliştirilmesiyle birlikte ham madde olarak metalürjistlerin kendi ürettiği; büyük ölçüde demir alaşımları, intermetalik alaşımların kullanılması, yüksek saflıkta başlangıç tozları yerine ucuz/kolay erişilebilir ferroalaşımlar kullanılması metalotermik redüksiyon yöntemiyle üretimi, avantajı bir pozisyona sokmaktadır. Metalotermik redüksiyon yöntemi direkt olarak reaksiyona giren malzemelerin öz 1sısına bağlı olup, proses ekzotermik karakterde gerçekleşmektedir. Proseste reaktan olarak oksitli metal tozları kullanılırken, redükleyici olarak Al-Mg-Si gibi metaller kullanılır [16-19].

Bu çalışmada oksitli demir kaynağı olarak tufal ve hematit kullanılmıştır. Tufal; üretilmiş çelik ürünlerin soğutulması esnasında yüzeyde oluşan metal oksitlerin karışımından oluşan atık bir malzeme olmasına rağmen, yüksek demir içeriğine sahip olması, onu demir kaynağı olarak kullanılabilmesi için olanak sağlar. Dünyada atık olarak meydana gelen tufal miktarının yıllık 13,5 milyon ton gibi büyük bir miktarda olması, geri dönüşüm yapılmasının gerekli olduğunu ortaya koymaktadır. Bu süreçte hammadde olarak tufalin kullanılması geri dönüşüm için alternatif bir kaynak sunmaktadır. Bunun yanı sıra metalotermik redüksiyon tekniğinin kullanımı ekonomik açıdan basit ve uygulaması kolay bir yöntem olması itibariyle konuya özgün değer katmaktadır [5], [11, 20-23]. Bu çalışma kapsamında, çeliğin dökümü sırasında ortaya çıkan tufalin metalotermik redüksiyon yöntemi ile farklı metaller kullanarak indirgenmesi sonucu ferromanganez üretimi gerçekleştirilmesi amaçlanmıştır.

\section{DENEYSEL METOT}

Deneysel çalışmalarda yöntem olarak metalotermik redüksiyon tekniği kullanılmıştır. Bu yöntemde metal oksitten oluşan yapı, oksijen afinitesi daha yüksek olan metalik bir malzeme ile reaksiyona sokularak indirgenir. 
Bahsi geçen yöntemde hangi malzemenin oksijen afinitesinin daha yüksek olduğu oksitlerin Ellingham diyagramına bakılarak belirlenir. Ellingham diyagramına göre aşağıda olan malzemelerin $\Delta \mathrm{G}$ değerleri daha negatiftir. Dolayısıyla reaksiyonlar ekzotermik karakterde gerçekleşir. Bu da reaksiyonun tetiklenmesi ile ilave bir enerji gerektirmeden kendi kendine ilerleyebilecek bir mahiyette olduğunu göstermektedir. Oksitlerin Ellingham diyagramı Şekil 1'de gösterilmiştir. Buna göre diyagramın en altında Al, Si, Mg ve Ca'nın olduğu, dolayısıyla bu malzemeler ile bütün oksitli yapıların redüklenebileceği görülmektedir.

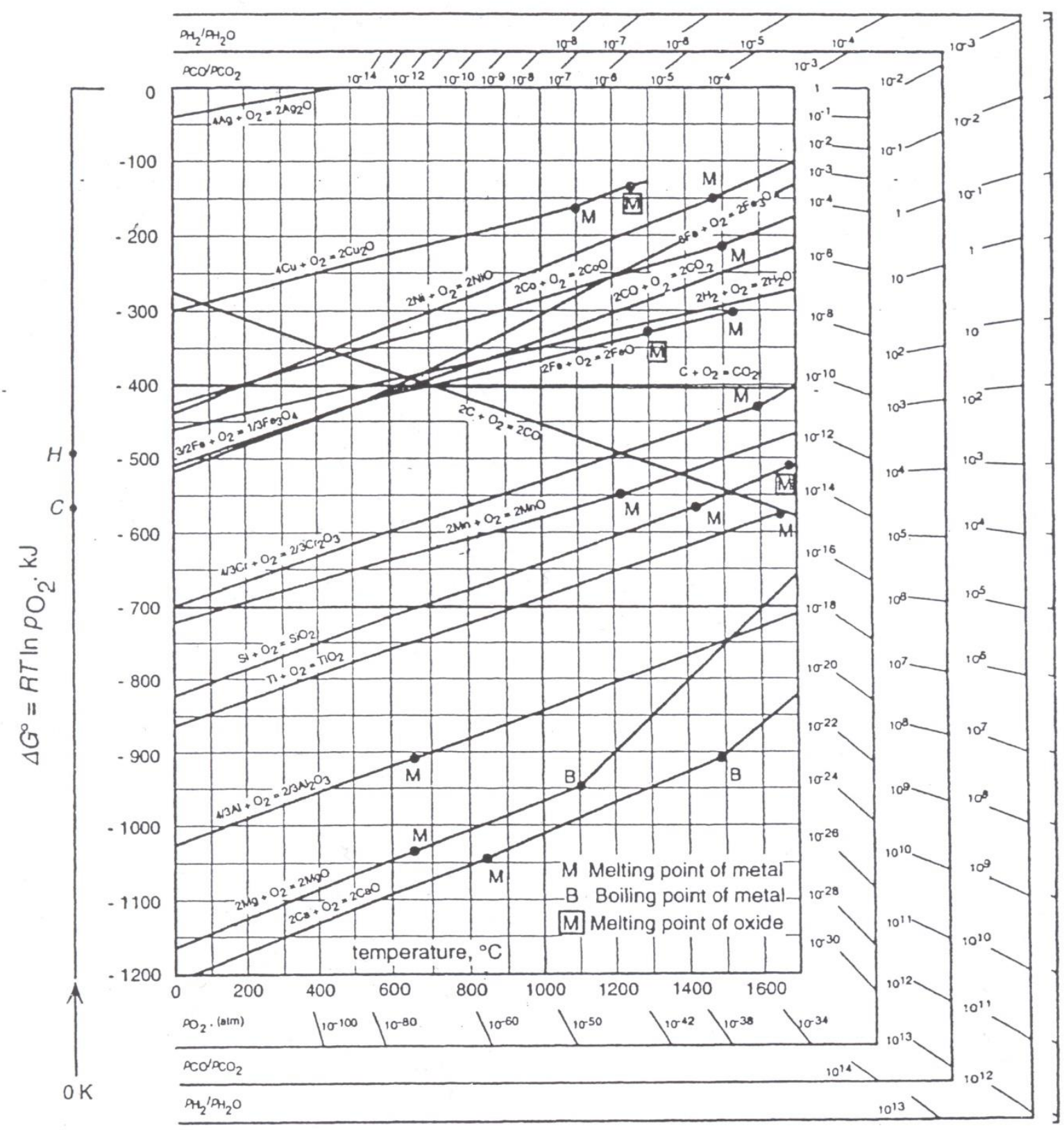

Şekil 1. Oksitlerin ellingham diyagramı[24]

Ellingham diyagramına göre demir oksitli yapıların $\Delta \mathrm{G}$ değerinin -500kj, MnO’nun ise -720kj seviyesinde olduğu görülmektedir. Aluminyum ve magnezyum için $\Delta \mathrm{G}$ değerleri sırasıyla $-1020 \mathrm{kj}$ ve $-1160 \mathrm{kj}$ olarak 
görülmektedir. Dolayısıyla Tufal, hematit ve manganezoksit bu malzemeler ile rahatlıkla redüklenebilecek konumdadir.

Deneysel çalışmalarda ilk olarak redüksiyon sistemleri termodinamik olarak modellenmiş sorasında, elde edilen bulgulara göre deneyler tasarlanmıştır. Tufal, Hematit ve $\mathrm{MnO}$ yapılarını redükleyebilecek Al ve Mg miktarları $\% 100$ stokiyometrik oran olarak belirlenmiş, sonrasında \%5'lik aralıklar ile bu oran \%100'den \%115'e kadar değiştirilmiştir.

Metalotermik redüksiyon genellikle oluşturulan karışımın yüzeyine direnç teli, elektrik veya lazer gibi 1Sı akışı sağlayan tetikleyiciler kullanılarak başlatılır. Reaksiyon tetiklendikten sonra enerji ihtiyacı olmadan kendiliğinden ilerlemektedir ve ısınma süresi tutuşma süresine kıyasla daha kısadır. Reaksiyonun gerçekleştiği ilk katmanda oluşan 1Sı bir sonraki katmana verilerek devamlılık sağlanır ve reaksiyona girmeyen kısmın kalmaması hedeflenir. Böylece bir taraftan ürün(metal) oluşurken diğer taraftan reaksiyon devam eder. Reaksiyon hızının yüksek olması ise daha ekonomik ve verimli bir üretim imkânı sağlar. Bu reaksiyonların gerçekleşebilmesi için; yüksek aktivasyon enerjisi ve çok yüksek derecede 1sı üretimi gerekir. Ferro mangan üretimindeki aşamalar, akış şeması Şekil 2'de verilmiştir.

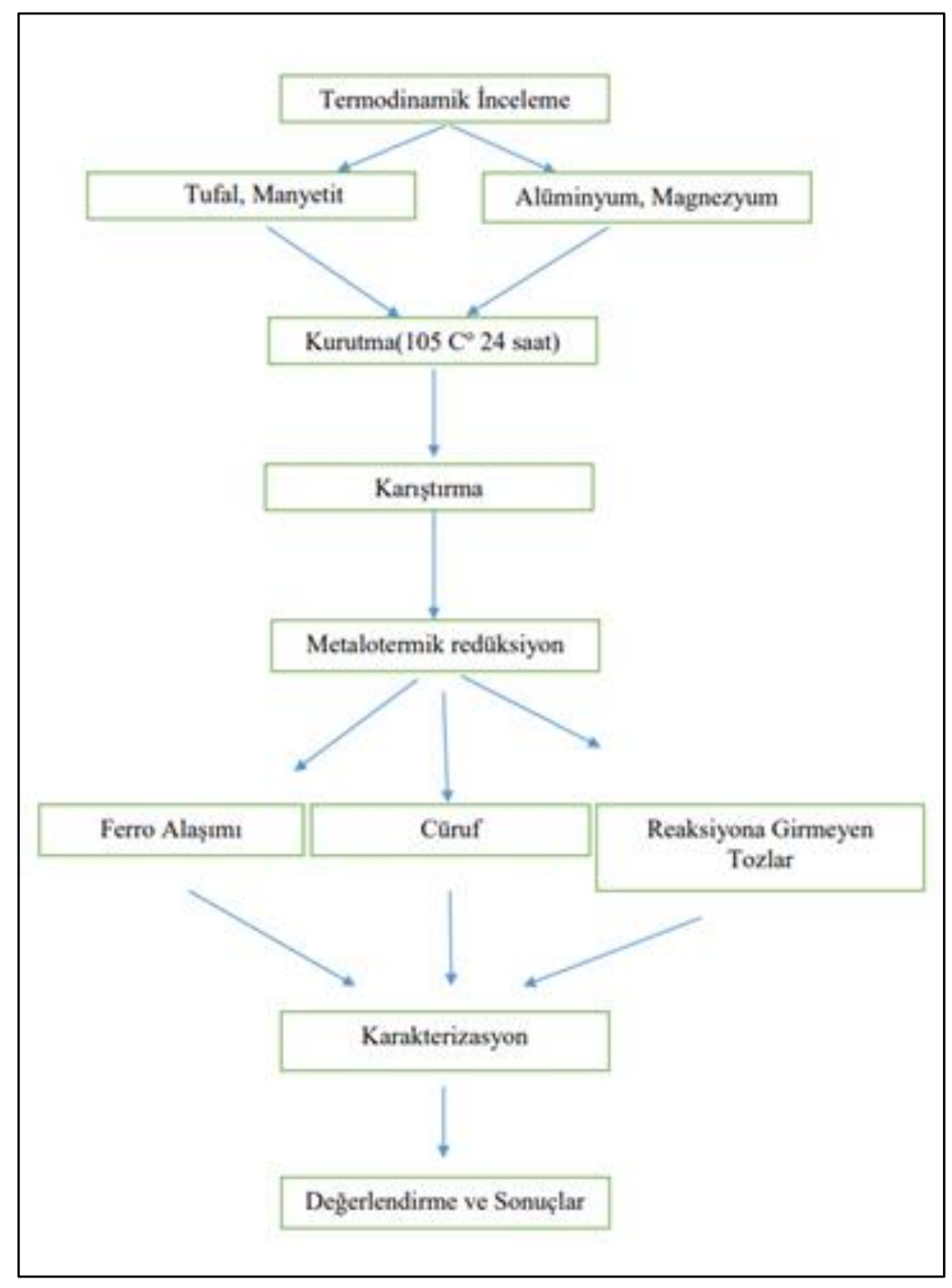

Şekil 2. Metalotermik redüksiyon yöntemi akış şeması 


\subsection{Malzemeler ve Hazırlama Teknikleri}

Ferromanganez üretimi için gerçekleştirilen çalışmalarda, demir kaynağı olarak Tufal ve hematit, manganez kaynağı olarak manganez oksit kullanılmıştır. Bahsi geçen numunelerden tufalin $\mathrm{Mg}$ ile redüksiyon şartları incelenirken, hematit Al ile indirgenmiştir. Tufal titrasyon yöntemi ile karakterize edilerek \%70.91 oranında demirli yapılardan oluştuğu belirlenmiştir. Tufaldeki demir dağılımı $\mathrm{Fe}^{0}, \mathrm{Fe}^{+2}$ ve $\mathrm{Fe}^{+3}$ yapılarından oluşmaktadır. Oksitli manganez kaynağı olarak 1344-43-0 CAS numaralı malzeme kullanılmıştır. Redüktan olarak kullanılan aluminyumun kimyasal analizi Tablo 1'de verilmiştir, diğer redüktan magnezyum ise \%99.7 safiyette ve $55 \mu \mathrm{m}$ boyutundadır. Deneylerde kullanılan tufal Şekil 3'te gösterilmiştir. Şekil 3'te görülen tufal öğütülerek ortalama tane boyutu 100 mikrona getirilmiştir.

Tablo 1. Aluminyum AAS Sonucları

\begin{tabular}{cccccccccc}
\hline Hammadde & $\mathbf{F e}, \boldsymbol{\%}$ & $\mathbf{C r}, \boldsymbol{\%}$ & $\mathbf{N i}, \boldsymbol{\%}$ & $\mathbf{Z n}, \boldsymbol{\%}$ & $\mathbf{M n}, \boldsymbol{\%}$ & $\mathbf{M g}, \boldsymbol{\%}$ & $\mathrm{Al}, \boldsymbol{\%}$ & $\mathbf{M o}, \boldsymbol{\%}$ & $\mathrm{Si}, \boldsymbol{\%}$ \\
\hline Al & 0,028 & 0,29 & 0,004 & 0,56 & 0,45 & 4,65 & denge & eser & 0,12 \\
\hline
\end{tabular}

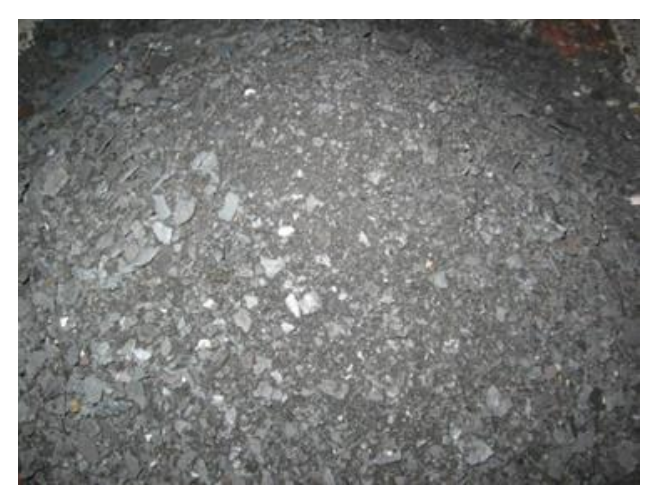

Şekil 3. Tufal görünüm

\subsubsection{Malzemelerin karakterizasyonu}

Alaşımların kimyasal bileşimini belirlemek için Thermoscientific Qualitative XL2 artı model XRF kullanılmıştır. Hammadde analizleri (AAS, Perkin Elmer Analyst 800) kimyasal analiz ve atomik absorpsiyon spektrometresi kullanılarak gerçekleştirilmiştir. Numuneler Turbula mikserde karıştırılmış, Nsmart ${ }^{\mathrm{tm}}$ EN $032 \mathrm{~N}$ EN 055N - EN 120N ETUV' de kurutulmuştur. Schimatzu marka 2 digit hassasiyetli terazide tartım işlemleri yapılmış, Yamer marka optik mikroskopta makro yapılar incelenmiştir. Elde edilen indirgeme cürufunun karakterizasyonu için XRD (X-1şını kırınım spektrometrisi, PANalytical PW3040 / 60) kullanılmıştır. Çözümlemeler Expert Highscore programı ile yapılmıştır. Termodinamik benzetim çalışmaları FactSage 7.1 programı ile gerçekleştirilmiştir.

\section{BULGULAR VE TARTIŞMA}

FeMn üretimi için yapılan çalışmalarda hematit aluminyum ile Tufal ise magnezyum ile redüklenerek, bulgular kıyaslanmıştır. Oksitli yapıları redükleyebilecek Al ve Mg miktarı \%100 stokiyometrik oran olarak 
belirlendikten sonra değişen redüktan stokiyometrilerinde karışımlar hazırlanmıştır. Hazırlanan karışım içerikleri Tablo 2'de gösterilmiştir.

Tablo 2. Hazırlanan karıșım içerikleri

\begin{tabular}{cccc}
\multicolumn{4}{c}{ Tablo 2. Hazırlanan karıșm içerikleri } \\
\hline Hematit, gr & Al, gr & MnO, gr & Stok.\% \\
\hline \multirow{2}{*}{15,08} & 6.077 & & 100 \\
& 6.381 & 3.842 & 105 \\
\multirow{2}{*}{ Tufal, gr } & 6.685 & & 110 \\
& 6.988 & MnO, gr & 115 \\
& Mg, gr & & Stok.\% \\
& 7.34 & & 100 \\
12.2 & 7.71 & 5.43 & 110 \\
& 8.08 & & 115 \\
\hline
\end{tabular}

Deneysel çalışmalara ilk olarak termodinamik modelleme çalışmaları ile başlanmış. FactSage programının reaction modülünden faydalanılarak reaksiyon entalpileri, buradan hareketle spesifik 1S1 (SI) değerleri hesaplanmıştır. Spesifik 1sı $\Delta \mathrm{H}_{298}$ değerinin, ürünlerin molar ağırlık toplamına bölünmesi ile belirlenmiştir.

$$
\begin{array}{lc}
\mathrm{Fe}_{2} \mathrm{O}_{3}+2 \mathrm{MnO}+3.33 \mathrm{Al} \rightarrow 2 \mathrm{FeMn}+1.66 \mathrm{Al}_{2} \mathrm{O}_{3} & \Delta \mathrm{H}_{298}:-1197190.4 \mathrm{SI}: 3109 \mathrm{j} / \mathrm{g} \\
\mathrm{Fe}_{3} \mathrm{O}_{4}+3 \mathrm{MnO}+7 \mathrm{Mg} \rightarrow 3 \mathrm{FeMn}+7 \mathrm{MgO} & \Delta \mathrm{H}_{298}:-1938313.5 \mathrm{SI}: 3162 \mathrm{j} / \mathrm{g} \\
\mathrm{Fe}_{2} \mathrm{O}_{3}+2 \mathrm{MnO}+5 \mathrm{Mg} \rightarrow 2 \mathrm{FeMn}+5 \mathrm{MgO} & \Delta \mathrm{H}_{298}:-1411857.1 \mathrm{SI}: 3345 \mathrm{j} / \mathrm{g}
\end{array}
$$

Hematitin aluminotermik redüksiyonu Eşitlik 1'e göre ilerlerken, tufalin magnezotermik reaksiyonu Eşitlik 2 ve 3'e göre ilerlemektedir. Eşitlik 1'de görülen SI değerinin 3109 j/g'lık değerle 2250-4500 aralığında kaldığı ve reaksiyonun, problemsiz bir biçimde ilerleyeceği öngörülmektedir. Ancak magnezotermik üretim koşullarında iki reaktanın yüksek Mg gereksinimi bir araya geldiğinde $4500 \mathrm{j} / \mathrm{g}$ değerini aşabilecek durumda görülmektedir.

Reaksiyonların spesifik ısı değerlerinin yanı sıra adyabatik sıcaklıkları ve muhtemel fazları aynı programın equlibrium moduyla incelenmiştir. Hematitin Tad sıcaklık değişimi artan Al stokiyometrisine göre Şekil 4'te verilmiştir.

Şekil 4'e göre 3 mol aluminyum ilavesi ile sistemin adyabatik sıcaklığı $2315^{\circ} \mathrm{C}$ 'ye çıkarken, sonraki miktarlarda düşüş göstermiştir. Ancak bu sıcaklık $1527{ }^{\circ} \mathrm{C}$ 'den büyük olduğu için redüksiyon sisteminin sorunsuz bir biçimde ilerleyebileceği görülmüştür. Hematitin Al ile indirgenmesindeki adyabatik koşullar belirlendikten sonra tufalin artan Mg stokiyometrisi ile redüksiyon koşulları incelenmiş, bulgular Şekil 5 (a) ve (b)’ de gösterilmiştir. 


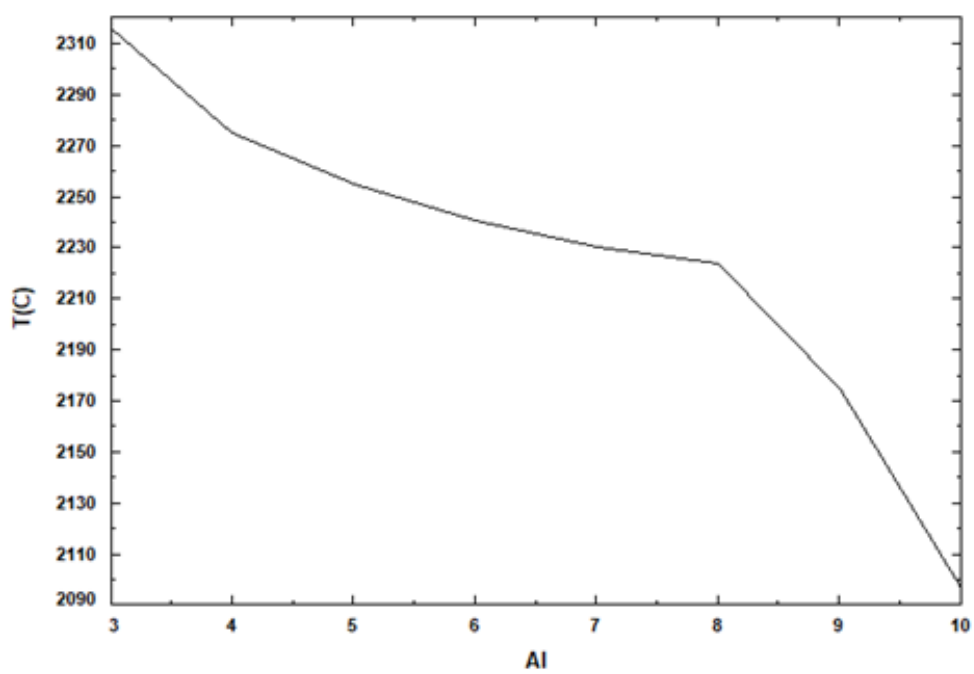

Şekil 4. Hematit, Manganez oksit sisteminin artan Al stokiyometrisi ile $\mathrm{T}_{\mathrm{ad}}$ değişimi

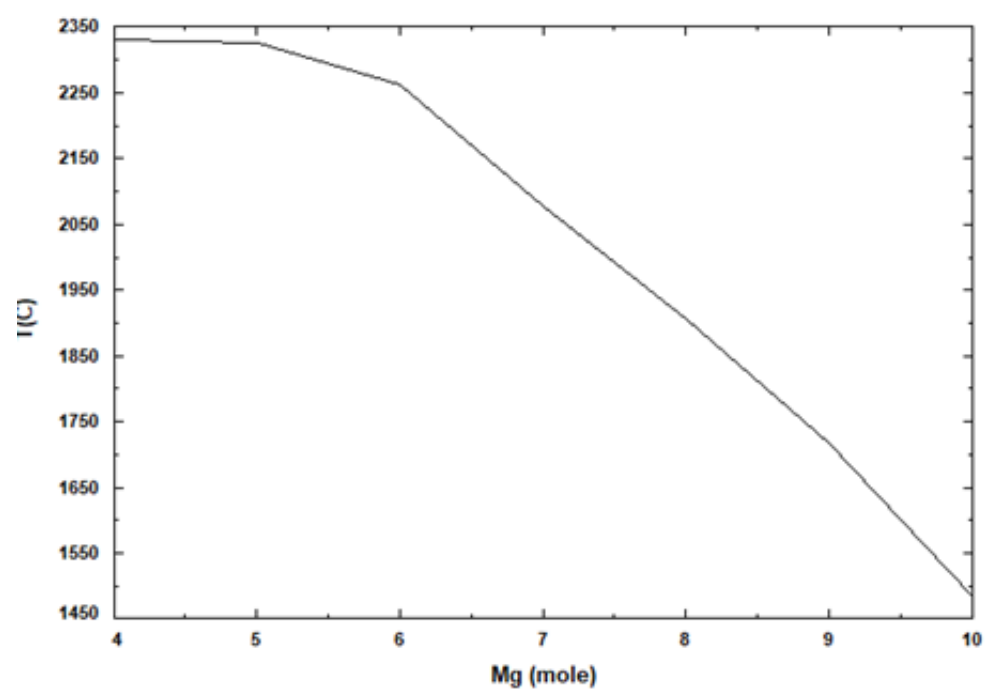

Şekil 5.a Tufal, Manganez oksit sisteminin artan Mg stokiyometrisi ile $\mathrm{T}_{\text {ad }}$ değişimi (a)Hematit, (b)Manyetit

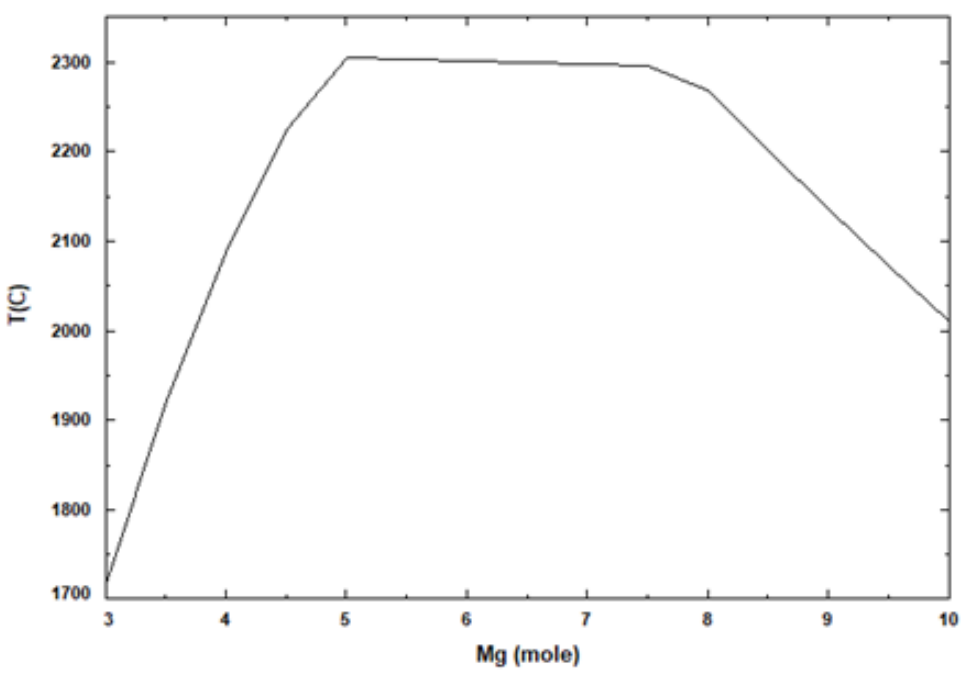

Şekil 5.b Tufal, Manganez oksit sisteminin artan Mg stokiyometrisi ile $T_{\text {ad }}$ değişimi (a)Hematit, (b)Manyetit 
Hematitin Mg redüksiyon koşullarında artan stokiyometrik oranla adyabatik sıcaklık $2320{ }^{\circ} \mathrm{C}$ 'den $1470{ }^{\circ} \mathrm{C}$ 'ye kadar düşerken, manyetitte 5 mole kadar yükselip bir süre sabit kalmış 8 mollük ilaveden sonra düşüş göstermiştir. Burada da $\mathrm{T}_{\mathrm{ad}} 2300^{\circ} \mathrm{C}$ 'ye kadar çıkarak $1527^{\circ} \mathrm{C}$ 'nin oldukça üzerinde bir değere ulaşmıştır.

Termodinamik simülasyon çalışmalarına muhtemel fazların tespiti ile devam edilmiş, bunun için FactSage programını equlibrium modülünden faydalanılmıştır. Bu çalışmada magnezotermik sistem modellenmiş hematit redüksiyonu Şekil 6'da verilirken, manyetit redüksiyonu Şekil 7'de verilmiştir. Hem Şekil 6, hem de Şekil 7'de $\operatorname{artan} \mathrm{Mg}$ stokiyometrisinde Fe her oranda sıvı fazda elde edilebilmektedir. Ancak Şekil 6'da 6 mol, Şekil 7'de 8 mol Mg oranıyla Mn'nin büyük oranda gaz faza geçtiği ve yapıdan uzaklaştığı görülmektedir. Bu durum Mg ile yapılan metalotermik redüksiyon işleminde sonuç üründen önemli oranda kayıp olabileceğini göstermektedir. Bu tespit yapılmasına rağmen simülasyon koşulları ile gerçek deneylerin uyuşmayabileceği ihtimaline karşıllk, magnezotermik deneyler baştan belirlendiği biçimde yapılmıştır.

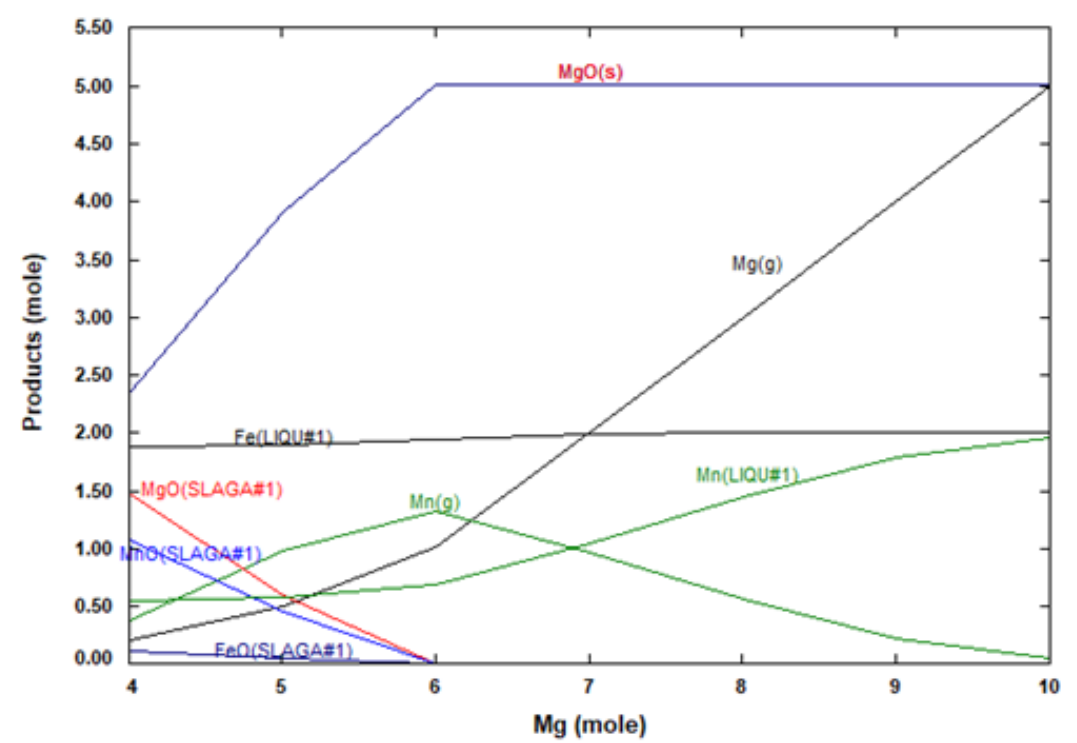

Şekil 6. Tufal, Manganez oksit sisteminin artan Mg stokiyometrisi ile oluşan muhtemel fazları (Hematit)

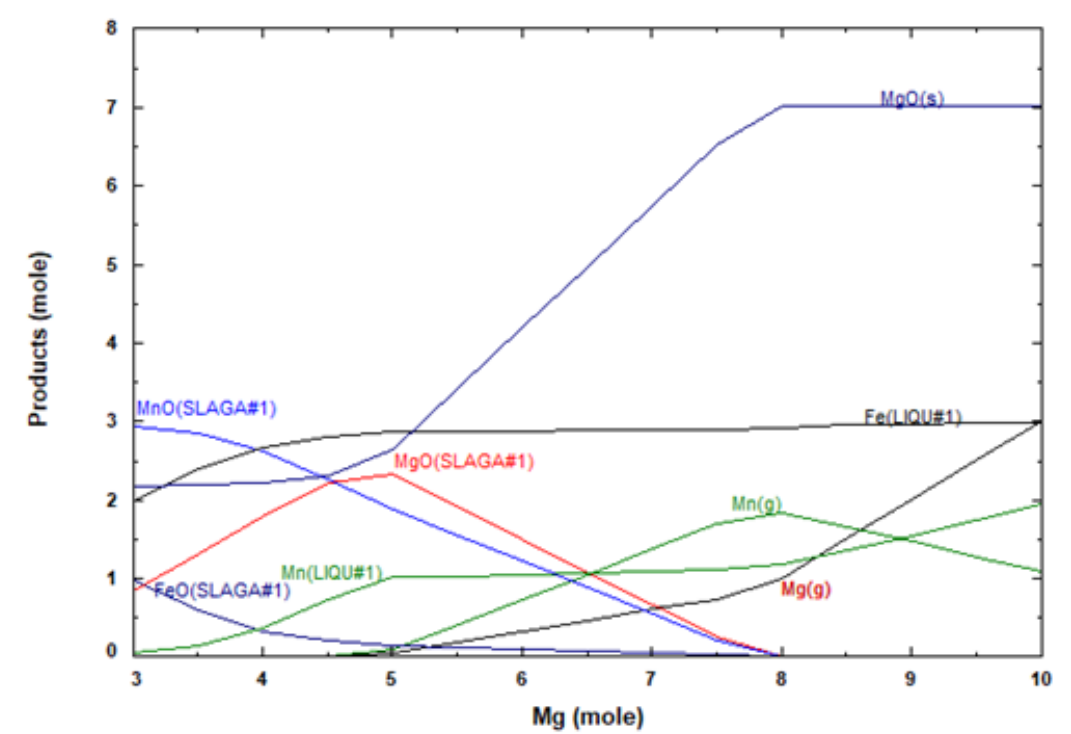

Şekil 7. Tufal, Manganez oksit sisteminin artan Mg stokiyometrisi ile oluşan muhtemel fazları (Manyetit) 
Termodinamik benzetim çalışmalarından sonra deneysel çalışmalara geçilmiş ilk olarak hematitin alüminyum ile redüksiyon koşulları incelenmiştir. Metal oluşum miktarları Şekil 8'de incelenirken, metal kazanım verimleri Şekil 9'da verilmiştir.

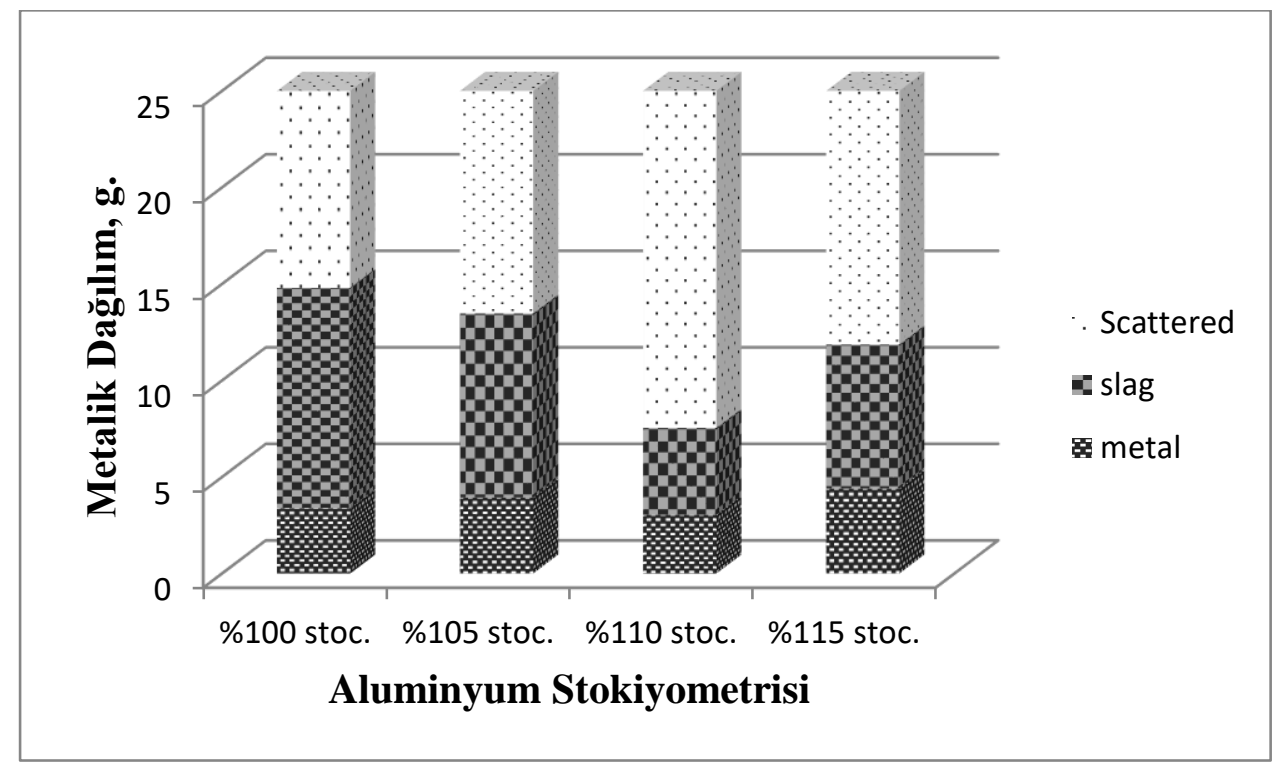

Şekil 8. Hematit deneyinde farklı Al stokiyometrileri için ürünlerin metalik dağııııı

Şekil 8 incelendiğinde metal oluşum miktarının oldukça düşük olduğu görülmektedir. Denklem 1'de verilen

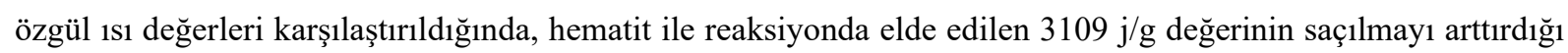
belirlenmiştir. Burada, en yüksek metal oluşum miktarı, Al'ın bir 1sı düşürücü olarak görev yaptığı \%115'lik stokiyometrik bileşimde görülmüştür. Verimler Eş. 5'e göre hesaplanmıştır.

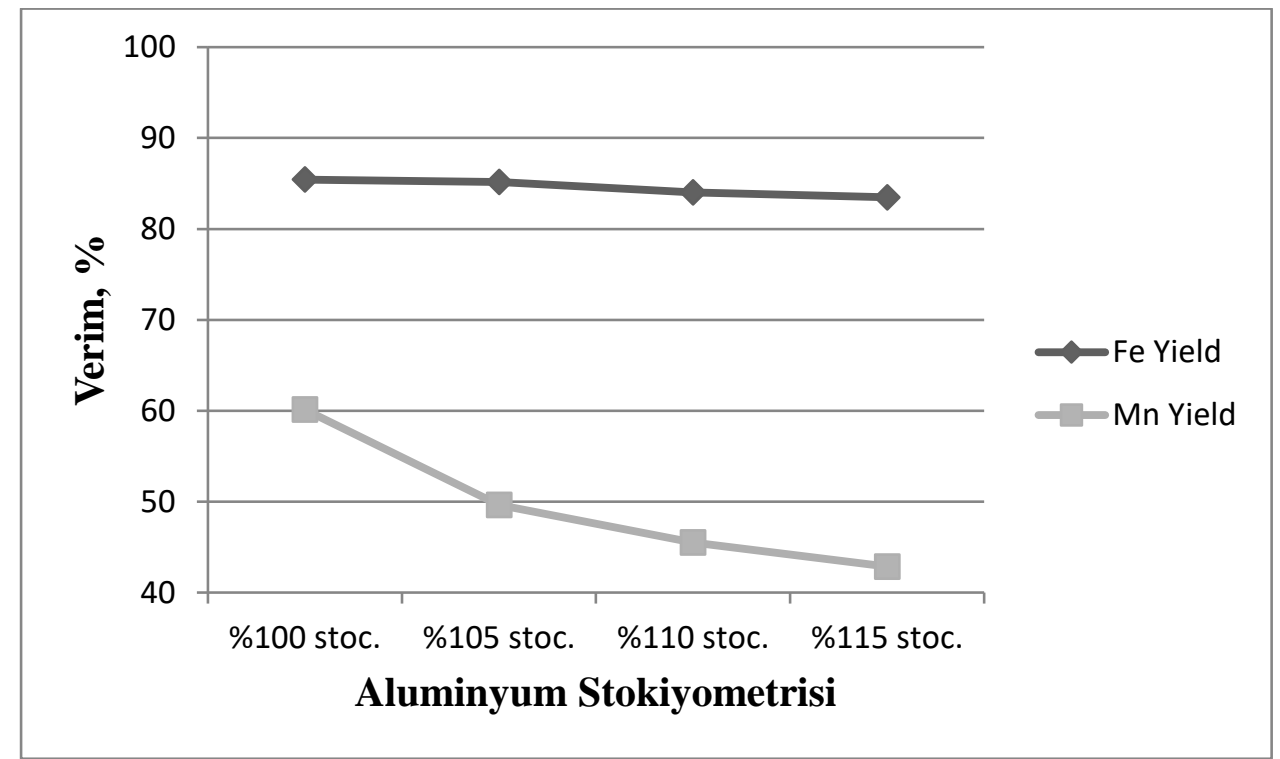

Şekil 9. Hematit deneyinde farklı Al stokiyometrileri için Fe ve Mn verimleri 
Demir kaynağı olarak hematitin kullanıldığ 1 bu sette demir verimleri \%90'ın altında değerler almış en çok \%85'lik verim elde edilebilmiştir. Mn verim değerleri \%115'lik stokiyometrik karışımda \%60'dan, \%42'ye düşerek artan Mg stokiyometrisi ile kötü sonuçlar vermiştir. Buna göre, hematitin reaksiyonu gerçekleştiren toplam enerjinin önemli bir kısmını kullandığı, dolayısıyla MnO'i indirgemek için yeterli enerjinin kalmadığ belirlenmiştir. Ayrıca üretilen enerji, metal oluşumundan çok saçılmaya neden olarak Fe verimini de olumsuz etkilemiştir. Karakterizasyon çalışmalarına XRD analizleri ile devam edilmiş, numuneler $\mathrm{Cu}$ k $\alpha$ spektrumunda incelenerek, cürufların XRD sonuçları Şekil 10’da sergilenmiştir.

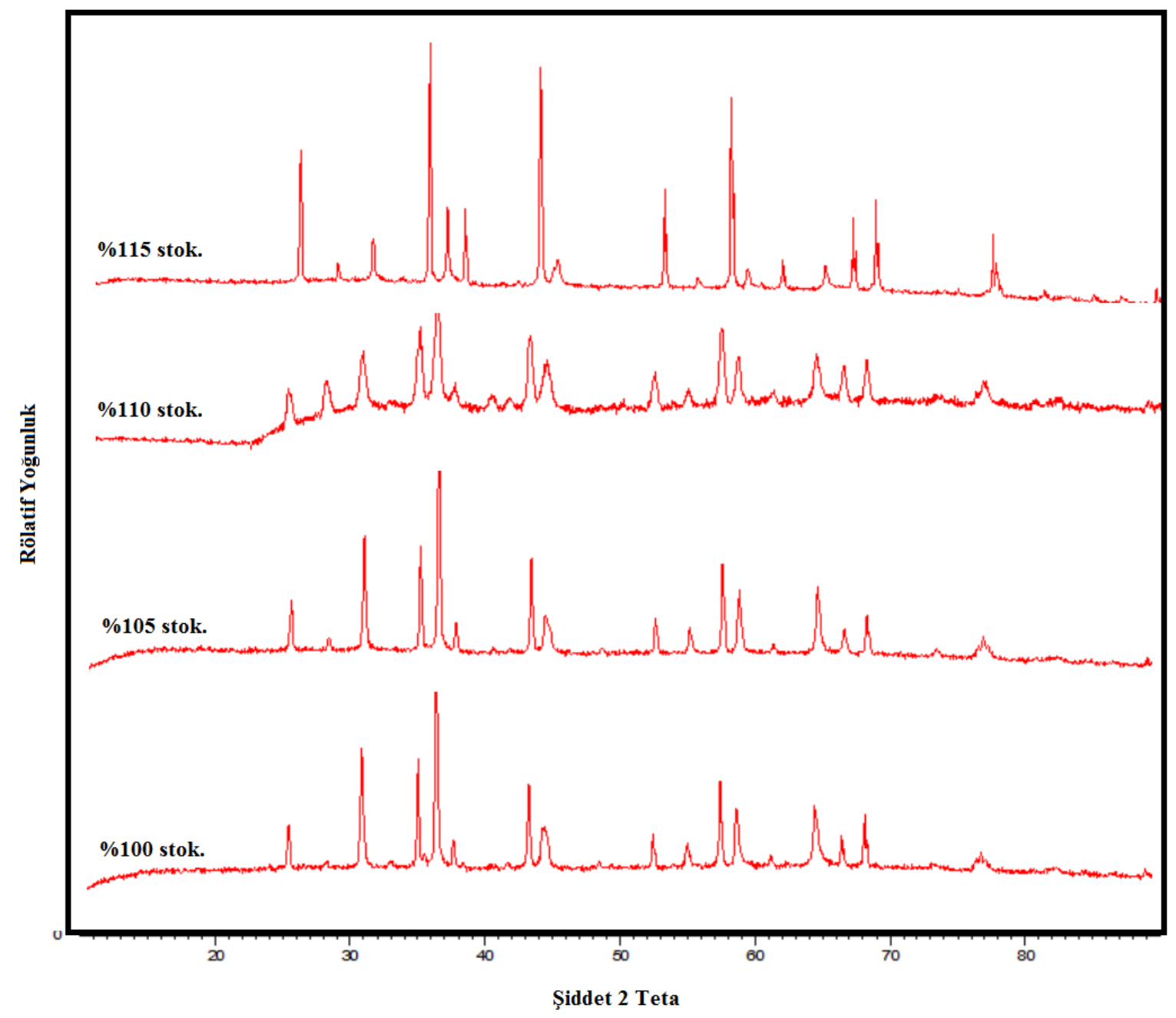

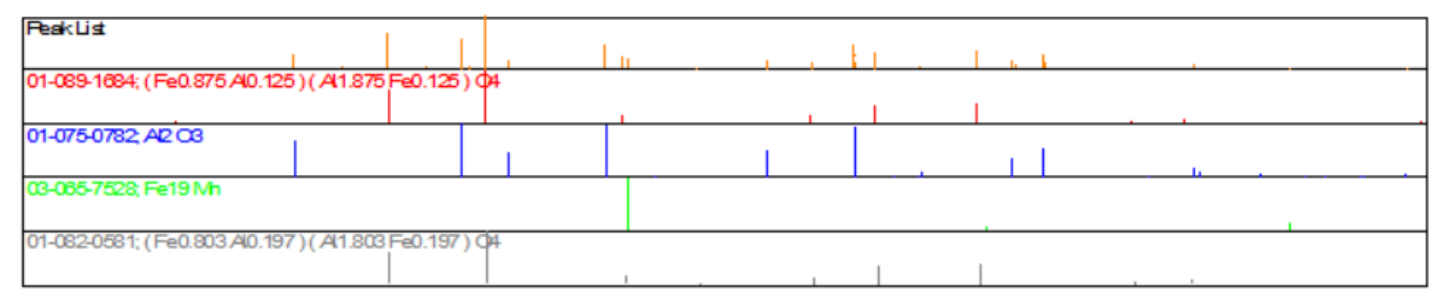

Şekil 10. Hematit deneyinde farklı Al stokiyometrileri için cürufların XRD paterni 
XRD paternleri incelendiğinde, ana fazın demir aluminat olduğu bunun yanı sıra bir miktar FeMn fazının da cürufa geçtiği görülmektedir. \%110 stokiyometrik aluminyum deneyi dışında bütün deneylerde benzer şiddette pikler elde edilmiş, bu deneyde piklerin şiddeti düşüş göstermiştir.

Optik mikroskop ile mikro yapı görüntüleme çalışmaları gerçekleştirilmiştir. Bu ekipmanda görüntü alabilmek için numune 180, 320, 600, 800 ve 1000 grid aşındırıcı boyutlarında zımparalanmış ve bir mikronluk elmas süspansiyonu ile parlatma işlemine tabi tutulmuşlardır. Bu işlem sonrasında numune distile su ve etil alkol ile yıkanmıştır. Parlatılan numuneler, keller çözeltisinde $\left(2 \mathrm{ml} \mathrm{HF}+3 \mathrm{ml} \mathrm{HCl}+5 \mathrm{ml} \mathrm{HNO}_{3}+190 \mathrm{ml}\right.$ saf su) dağlanarak, görüntülenmeye hazır hale getirilmiştir. Bu süreçte en yüksek manganez veriminin görüldüğü \%100 stokiyometrik bileşimdeki numune incelenmiş, bulgular Şekil 11'de gösterilmiştir.

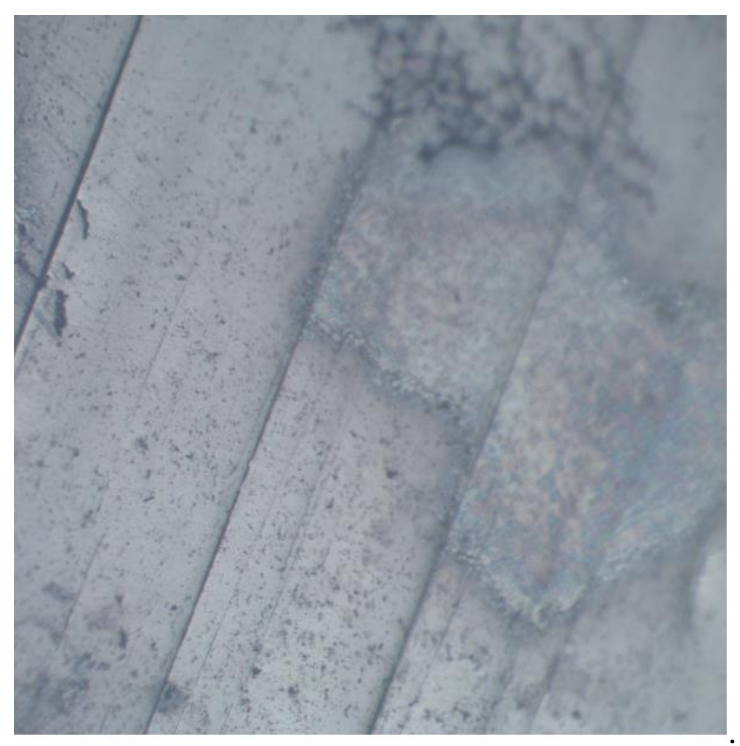

Şekil 11. \%100 stok. Al içeren numunenin optik mikroskop görüntüsü

Şekil 11'e göre demir matrisi üzerinde farklı kontrastlarda yeni fazların oluştuğu görülmektedir. Buna göre manganez içeren yapılar bu bileşim değerinde başarı ile elde edilmiştir. Bu kontrastı oluşturan yapının XRD'de görülen FeMn'dan oluştuğu düşünülmektedir.

Deneysel çalışmalara magnezotermik deneyler ile devam edilmiş, ancak termodinamik çalışmalarda öngörüldüğü gibi metalik bir yapı elde edilememiştir. Mg toz boyutunun oldukça düşük olması spesifik 1sıyı daha da arttırmış zaten yüksek olan bu değer yüksek oranda gazlaşma yaparak malzeme kaybına sebebiyet vermiştir. Metalik bir yapı elde edilemediği için bu numuneler ile ilgili karakterizasyon çalışmaları gerçekleştirilememiştir.

\section{SONUÇLAR}

FeMn üretimi için yapılan çalışmada hematit Al ile redüklenmiş Fe \%85, manganez ise \%60 verimle kazanılabilmiştir. İndirgeyici olarak magnezyumun kullanıldığı deneylerde metalik bir yapı elde edilememiş, termodinamik incelemelerde bunun sebebi araştırılmış ve yüksek spesifik ısı değerlerinin malzemeleri gaz faza 
geçmeye teşvik ettiği bulgusuna ulaşılmıştır. Aluminotermik deneylerde stokiyometri \%100'den \%115'e kadar \%5'lik aralıklarla yükseltilmiş, ancak en müspet sonuç \%100 stokiyometrik bileşimde elde edilmiştir. Termodinamik simülasyonlar incelendiğinde tufalin de aluminyum ile redüklenebileceği, bunun yanı sıra her iki redüktanın bir arada olduğu koşullarda daha yüksek verimle arzulanan alaşımın elde edilebileceği öngörülmektedir.

\section{TEŞEKKÜR}

Makalenin termodinamik incelemelerindeki katkılarından dolayı yazarlar Faruk Kaya’ya teşekkür eder.

\section{KAYNAKLAR}

[1] Cota TG, Reis EL, Lima RMF, Cipriano RAS (2018) Incorporation of waste from ferromanganese alloy manufacture and soapstone powder in red ceramic production. Appl Clay Sci 161:274-281.

[2] Ghafarizadeh B, Rashchi F, Vahidi E (2011) Recovery of manganese from electric arc furnace dust of ferromanganese production units by reductive leaching. Miner Eng 24(2):174-176.

[3] Bafghi MS, Zakeri A, Ghasemi Z, Adeli M (2008) Reductive dissolution of manganese ore in sulfuric acid in the presence of iron metal. Hydrometallurgy 90(2-4):207-212.

[4] Falodun OE, Oke SR, Okoro AM, Olubambi PA (2019) Characterization of cast manganese steels containing varying manganese and chromium additions. Mater Today Proc 28:730-733.

[5] Cho S, Lee J (2008) Metal recovery from stainless steel mill scale by microwave heating. Met Mater Int 14(2):193-196.

[6] Coetsee $\mathrm{T}$ (2018) $\mathrm{MnO}$ reduction in high carbon ferromanganese production: practice and theory. Miner Process Extr Metall Rev 39(5):351-358.

[7] Surup GR, Trubetskaya A,Tangstad M (2021) Life cycle assessment of renewable reductants in the ferromanganese alloy production: A review. Processes 9(1):1-19.

[8] Cerra FMA, Da Silva Lima MN, Araújo WS, Da Silva MJG (2019) Characterization and comparative analysis of corrosion resistance of 4 high manganese steels models in aqueous solution of $\mathrm{NaCl}$. Mater Res 22(1):1-13.

[9] Subhi AD, Abdulrazaq OA (2007) Phase Transformations of Hadfield Manganese Steels Eng Technol 25(6):808-811.

[10] Yeşiltepe S, Buğdaycı M, Yücel O, Şeşen MK (2019) Recycling of alkaline batteries via a carbothermal reduction process. Batteries. https://doi.org/10.3390/batteries5010035

[11] Yeşiltepe S, Şeşen MK (2020) Production of composite pellets from waste coffee grounds, mill scale and waste primary battery to produce ferromanganese; a zero waste approach. Acta Metall Slovaca 26(2):4548.

[12] Bugdayci M, Alkan M, Turan A, Yücel O (2018) Production of Iron Based Alloys from Mill Scale through Metallothermic Reduction. High Temp Mater Process 37(9-10):889-898.

[13] Öncel L (2020) Production of Ferromolybdenum from Mill Scale via Aluminothermic Process. Sinop Üniversitesi Fen Bilim Derg 5(1):64-76. 
[14] Bugdayci M, Deniz G, Ziyreker C, Turan A, Oncel L (2020) Thermodynamic modeling and production of FeCo alloy from mill scale through metallothermic reduction. Eng Sci Technol Int0 J 23(5):12591265.

[15] Öncel L (2020) Production of ferronickel from mill-scale via metallothermic process. El-Cezeri J Sci Eng 7(2):824-834.

[16] Turan A, Bugdayci M, Yucel O (2015) Self-propagating High Temperature Synthesis of TiB2. High Temp Mater Process 34(2):185-193.

[17] Akkas B, Alkan M, Derin B, Onuralp Y (2010) Production of Zirconium Diboride Powder by Self Propagating High Temperature Synthesis. Adv Sci Technol 63:251-256.

[18] Merzhanov AG (2004) The chemistry of self-propagating high-temperature synthesis. Journal of Materials Chemistry 14(12):1779-1786.

[19] Odabaş ÖC, Buğdaycı M, Kan S, Turan A, Yücel O (2021) Effects of reductant type on the combustion synthesis of NiB. Solid State Sci. https://doi.org/10.1016/j.solidstatesciences.2020.106447

[20] Murthy YI (2012) Stabilisation of expansive soil using mill scale. Int J Eng Sci Technol 4(2):629-632.

[21] Yucel O, Demirci F, Turan A, Alkan M (2013) Determination of direct reduction conditions of mill scale. High Temp Mater Process 32(4):405-412.

[22] Rajshekar Y, Pal J, Venugopalan T (2018) Mill scale as a potential additive to improve the quality of hematite ore pellet. Miner Process Extr Metall Rev 39(3):202-210.

[23] Martín MI, López FA, Torralba JM (2012) Production of sponge iron powder by reduction of rolling mill scale. Ironmak Steelmak 39(3):155-162.

[24] TURAN A, BUĞDAYCI M (2020) CoB Ön Alaşımlarının Alüminotermik Redüksiyon Yöntemiyle Üretilmesi ve Termokimyasal Modellenmesi. El-Cezeri Fen ve Mühendislik Derg 2020(2):436-447. 
